\title{
Refurbishment Informational School Architecture
}

\author{
A Base to an Educational Information Service
}

\author{
Antonio Castro and Leonel Santos \\ Centro Algoritmi, University of Minho, Portugal \\ antonio.castro@algoritmi.uminho.pt, leonel@dsi.uminho.pt
}

\begin{abstract}
Large technological developments have occurred over the last three decades and their impacts are affecting the management of educational systems. With cloud computing, we now have an opportunity to reshape architectures. In this paper, we present a model-based redesign for next generation technologies, to act on educational management at a school level. This redesign model respects existing system architectures, increases and organizes school communication channels and includes an intelligence element. Key performance indicators were included in an intelligence element to allow peer benchmarking and provide a refresh referential. The new referential is included in the architecture core element and will allow schools to respond to the informational needs of next level analytical engines. This redesign model intends to create conditions to develop the holistic analyses of educational management. Based on Stafford Beer's work, it is also in the intelligence element that the interaction with the school's internal and external environments is developed. Stafford Beer's Viable System Model (VSM) is a conceptual framework that can be used to diagnose and resctructure organizations. In this work, we used the VSM to remodel the informational architecture of school management in Portugal.
\end{abstract}

Keywords: Educational management, school management system, Viable System Model, educational information system.

\section{Introduction}

Schools are units of an educational system with a great degree of complexity. They are differentiated and independent, and their autonomy is growing. Educational management, evolved mainly through technological development and the way information technology (IT) is supporting educational management processes, brings a greater capability to school leaderships.

With the introduction of personal computers in schools in the 1980s, these 'cognitive prostheses' were gaining position and can be considered today as part of daily school life. Some key processes of school organization have been automated and supported by IT. Over the last three decades, technologies have evolved, increasing their communication potential, reducing device size and increasing graphical capabilities, as well as storage and communication capacity. The model, however, has been the same throughout the whole process: the Van Neumann model [1]. The same applies to

D. Passey, A. Breiter, and A. Visscher (Eds.): ITEM 2012, IFIP AICT 400, pp. 119-130 2013.

(C) IFIP International Federation for Information Processing 2013 
changes in management resulting from the introduction of technologies into the process. There is a growth in knowledge and technology, there is a greater organizational control of the school as an organization and, slowly, we are witnessing a shift in focus from the management of technology to the management of information. As in evolutionary stages [2], there is a change in technology, but the movement is still the same at each technological change. This path is evolving, but the device's principles remain based on Van Neumann and technological adaptation remains based on Nolan. What changed, essentially, was broadband communications. This must have an impact on management too, at school level and its articulation to all educational fields.

Accompanying technological developments, schools were themselves equipping and developing their own informational and technological architectures. They have been developing their own information system architecture [3]. The combination of these factors, technological developments and templates, consolidated in the schools' informational system architectures, opens perspectives to our work and raises a question - how can we capitalize on the IT present at school level, to modernize, improve and monitor performance?

The use of laptops as work tools has a direct influence on lesson preparation, on the teacher and the pupil's role, on the relationship between technologies and, for obvious reasons, on the school management process. Educational management substantiates an informational integrative perspective supported by IT [4]. The informational and technological strategic alignment [5] must also be prepared to readjust in an analogous manner to this evolutionary process. In a new phase of technology inflection, it seems relevant to define and develop a systemic solution that allows schools to monitor changes and realign strategies.

It should create conditions for schools to adapt to change, respecting their particular realities, in organizational, technological and social environments. It is known that technologies have their own life cycles [2], and this applies to systems architectures as well. It was in the field that answers were looked for with conditions that respected schools' autonomy, defending schools' creativity and entrepreneurship. In this work, a standard solution for all schools is not an advocate hypothesis. Instead, an alternative hypothesis was followed: looking for responses in goal measurement, in its parameters and in the fashion of their application.

The evolutionary impulse, as is happening with cloud computing, will allow humanity to share information in a manner never possible before. This technological evolutionary impulse can encourage organizational and technological restructuring of schools. This moment can help the school to reinvent itself in its own organization. It can help it to aim for change, while keeping its viability within the varied and greatly complex panorama of educational management. The hypothesis following looks to endow schools with the ability to change, while preventing the crumbling of the present architecture. This work intends to be capable of proposing a way to reshape architectures, following these premises and researching for an architecture model that can successfully cope with change.

The path that was followed respects pre-existing realities, pointing out the technological change as an important moment to review the school's relationship with its environment and take advantage of this moment to make adjustments, adaptations or, 
if necessary, interventions to warrant it as an efficient technological support. That was the way followed, to define and suggest an architectural framework suitable to understand and extract information with key performance indicators (KPIs) as a base to an educational scholarship building. In a few words, a KPI list is given for peer benchmarking; a particular framework architecture is advised, but schools are independent to choose the way they do the job. To join this project, schools just needed to be able to provide data values in a proper format.

This paper aims to present an application of a cybernetic model that serves the informational and technological architectures of the school, in support of the educational system in its management process; a model that supports educational unit autonomy; a model that supports the variety and complexity present in schools; a model that works as a center to adaptation to changes, as it is demanded in contemporary contexts. It applies the Viable Systems Model [6]. The Viable System Model (VSM) is not a new idea. It was created by Stafford Beer about 30 years ago and has been used as a conceptual tool to understand organizations and support management of change.

\section{Viable Systems}

Viable means: passable; that can be traveled through; or that which is able to survive on its own. An organization is viable if it is able to survive by itself in a given environment. An organization is viable if it is independent, autonomous and if it has an identity of its own. A viable system requires adaptability and respect for autonomy. Its components must be able to communicate effectively.

\subsection{Variety and Complexity}

On the complexity of organizations, it is customary to use a wide variety of information. It is a useful guide to study at which points information is amplified and where it is attenuated. The management of variety becomes important because much of the information is irrelevant for the purpose of carrying out the task. What is needed is to act in both ways: attenuation and amplification [7]. Attenuation normally affects the collection of information and its filtering, while amplification affects the dissemination of information to an organization's internal and external environment.

Processes of great variety bring with them complexity. To deal with the variety and complexity of information, a system that guarantees a balance between actions of long-term (the strategic part) and those of short-term (daily operational activities, coordination, etc.) is of critical importance. The systemic work must ensure that variety and complexity adapt to the constraints of external environments, while maintaining an appropriate degree of internal stability.

\subsection{Autonomy and Viability}

Autonomy and viability presuppose a condition of independence and ability to adapt to change [8]. It is what schools are seeking in Portugal: to develop autonomy [9] and 
find the ability to adapt to change, responding to contemporary demand. Autonomy involves the ability to learn and to live with one's own rules and responsibilities. Viability implies that those rules allow for positive work, controlling operations in a positive way. The set of rules, the conduct and the behaviour should allow all components to solve their problems independently, providing decision-making to its various elements.

\section{The Viable Systems Model}

A Viable Systems Model (VSM) is now also a tool for studying a structure's organization [10]. VSM is a model centered on recursion relationships to support the viability of organizations. It is designed to respond to the environmental changes in which it is involved and to prolong its topicality. The main characteristic of this model is that its systems are recursive, adaptable and able to survive, even in environments of great variety and complexity. The system must have the ability to adapt to change and to generate, by itself, metamorphoses that respond positively to external and internal environmental changes, thus keeping itself feasible over time. VSM is a model that grants autonomy and ability to communicate in all its components. This model also ensures viability and is composed of five elements, adaptable and able to survive changes in the environment. These elements are focused in two main situations. One concerns operations and the immediate time. The other focuses on future prospects for the organization - how it will evolve, which paths it should follow and what position should be assumed in future actions. In a highly summarized form, the top management (Sub-system 5) assigns work of an operational nature (Sub-system 1), coordination (Sub-system 2), while controls, checks and audits (Sub-system 3) deal with the environmental conjecture guidance system (Sub-system 4) and defines and establishes political dimensions. Its aim is to enable a structure that provides people with resources and communication channels to constitute actual iterations [11].

\subsection{Two Roles for Viability - The 5 Sub-systems for Organizations}

The VSM corresponds to 5 recursive sub-systems to maintain systemic stability. In five words: operations, coordination, monitoring, intelligence and policy.

Sub-system 1: Operations. These correspond to primary activities; they have responsibilities in producing records, the core of this recursive model. Recursion in VSM is represented in Sub-system 1. The primary tasks have their own information channels to communicate with their environment in terms of daily requirements.

Sub-system 2: Coordination. A viable system also has sub-systems dedicated to the coordination of added value functions and surrounding primary activities. In summary, the second sub-system is a system of rules and procedures that should allow multiple systems to resolve their own problems, providing them with decentralised decision-making capacities. 
Sub-system 3: Checks and Controls. Controls: This sub-system handles daily activity management in the base system, sub-system 1, in order to ensure the operational efficiency in the organization. This sub-system relies on information received directly from management through two-way channels. Checklist: Another important aspect is the verification channel, responsible for auditing and monitoring, which connects directly to the operational activities of sub-system 1 . The label 'audit' means the ability to examine activities in sub-system 1 .

Sub-system 4: Intelligence. The basic tasks of sub-system 4 are research and development, market research and organizational planning. It should maintain a correct balance between external environments and primary activities, supplying the organization with regard to market conditions. External factors are likely to be relevant in the future of the organization and, secondly, to assume an identity and to communicate into the internal environment. It intends to propose bridges between internal developments and external trends.

Sub-system 5: Politics. Sub-system 5 supplements the viable system and has the task of handling politics. It assumes the role of a judge for the organization. Compared to the complexity of the parts of the organization, this function is, by definition, a lowlevel process.

\section{The VSM and School Informational Architecture}

The information architecture model designed and proposed here is based on Beer's VSM. To be a part of the cloud, each school can have its own architecture, although information needs must be respected. The model adaptation has five elements and covers all schools' existing processes. From operations to strategies, passing through communications, the VSM adaptations are designed in terms of approach to the school processes of daily activities and relationships between processes. This informational architecture remodelling respects current realities and assumes that each school is autonomous in decision-making. Each school has its own educational project, its own rules and its own curricular project. Each school decides how it should communicate with the community. Each school decides how to control financial, curricular and pedagogical processes, and even the software management to support them.

In this project, the way in which schools collect their data is free for them to choose. It can even be human-based if they make this possible, but all schools aggregated to the project must be ready to provide results based on the KPIs present in the advised intelligence sub-system. Providing results should be done through a recursive structure, which obtains information produced at an operational level and measures it with educational KPIs - what teachers teach, what students learn in the conditions created for learning development at each school and so on. The facilitation of information uses a recursive structure too, aiming to support political decisions and to show all administrative levels how relevant they are to school trends. This model is 
intended to be suitable for the recording and collection of informational transactions, control and monitoring, and to be able to produce 'intelligence' in supporting the school's environmental adaptability. The viable system model application proposed was inspired by the school performance feedback system (SPFS) theoretical framework developed by Visscher [12].

Sub-system 5: Politics. The executive school board and the school director have the responsibility to define political and strategic school orientations. This body produces strategic documents such as the school's educational plans. It is advocated that policy definition must be strongly supported by the aggregated information system and its strategic orientations [13]. The decision-making process must be affected by information provided by the school management system in sub-system 4 .

Sub-system 4: Intelligence. This element is responsible for analytical tools and management map production, based on educational KPI measurement and external interactions (with government institutions, parents, etc.). The KPIs imply an automated readiness to allow its measurement. These applied indicators result from Portuguese educational inspections. The information required by the Ministry is provided by this element. This is also the element in which performance results must converge. It is responsible for converting the information into knowledge at a school level. In order to do it successfully, information capture must be KPI-targeted.

Sub-system 3: Control and Monitoring. Audit and control, in the Portuguese education system, are the responsibility of the education inspection (IGE). In spite of this, internal control sub-systems may be defined in the school environment. Examples can include control systems responsible for monitoring attendance, objective accomplishment, school abandonment or others.

Sub-system 2: Coordination. Coordination activities are supported here and automated with course coordination, subject pivots, and departments are provided for by this element. Coordination instruments for teachers's schedules, class sizes, laboratories and classroom use are also included here. Meetings and correspondent records are a coordination activity here too.

Sub-system 1: Operations. All subjects related to daily activities must have their records in this element, such as teaching activities and teaching activities' support systems, their planning in daily records as well as evaluation moments and disciplinary issues.

Communications. At the moment, schools use institutional emails, newsletters, institutional websites, social networking platforms, Moodle (in locations specifically selected for its applications) and the student digital booklet. The way in which each component of the VSM performs its function is very dependent on how it communicates within itself and with the other elements. The four communication VSM areas carry information from the school management to the operations unit and between 
internal and external environments. The communication channels used in schools are distinct and have different functionalities, including a broadcast and an individual function. They should take into consideration the ability to mitigate or amplify a certain amount of relevant information. They are vehicles for communicating between components of the VSM. Supporting communication into and out of school is a vital element, structural in terms of its autonomy and its viability. These channels also include in themselves a great variety. For example, to have an effective student assiduity control, it is necessary that this control communicates quickly and efficiently an assiduity failure. There is a need to communicate this failure both to the interior and the external environment. With teachers' assiduity control arises the need to communicate quickly or in advance so that a class replacement can be carried out.

\section{$5 \quad$ Including Key Performance Indicators in the Intelligence Element}

The first problem that arises in defining indicators is their selection. There are questions related to their nature, such as whether they should arise from a theoretical framework, or if they should simply be selected from already tried and tested sources. The task of establishing a typology of indicators should be understood as a permanent work in progress [14]. In this project the decision regarding indicator selection was to use the indicators from Portuguese schools' assessment [15], which is based on the Scottish work "How good is our school". It was decided that the list would be complemented by some indicators used by the OECD [16] to enrich the monitoring system.

Five domains of action were defined and each one has its own parameters. The five domains are: Results; Educational Service Provision; Organization and School Management; Leadership; and Extras. The KPIs for each domain follow.

\subsection{Domain 1 - Results}

\section{Academic Success:}

- Progression, retention and drop-out rates per school year, year of schooling and study cycle.

- Student transition rates, with recovery plans and monitoring - according to school year, level of education, course and year of schooling.

- Transitional rates for pupils with special educational needs.

- Distribution of classification levels in secondary school examinations.

- School curricular subjects with success and failure identified.

- Internal assessments versus external result comparisons; evidence at the K-4 and K-6 levels.

- Internal assessments versus external result comparisons; national examinations at the K-9 level (Portuguese language and mathematics).

- Based on national secondary examination results, comparisons of internal student classification versus external rankings.

- Drop-out related to school performance.

- Number of constraints identified in school drop-out. 


\section{School Life Participation:}

- Frequency of parents' attendance.

- Frequency of parents ' and class delegates' participation in evaluation meetings.

- Percentage of institutional email exchange between the different elements of the educational community (by groups, clusters and between groups).

- Percentage of activities proposed to the activities run in the annual plan by the student community and parents.

\section{Behavior or Discipline:}

- Percentage of disciplinary proceedings, by study cycles.

- Typology of the nature of disciplinary processes.

- Percentage of visits to the rules and procedures document on several platforms (the web and Moodle).

- Frequency of relapses.

- Frequency of attendance and punctuality failure.

\subsection{Domain 2 - Educational Service Provision}

\section{Overall:}

- Number of curricular subjects taught.

- Number of subject plans submitted.

- Number of subject groups, and interdisciplinary activities in the annual plan of activities.

- Measurement of coordination goals achieved.

- Teaching staff articulated in the activities' annual plan.

- Number of individual student project requests.

- Periodicity of meetings: between teachers, teachers and parents, psychology and guidance service (PGS) and teachers, PGS and parents, and the parents' association.

\section{Accompanying of Teaching Practice in the Classroom:}

- Frequency of lesson plans (number of lesson plans versus number of classes provided for).

- Number of digital resources used by curricular theme.

- Rate of completion in programmed planning.

- Mid-term evaluation of curricular class projects.

- Number of assessment instruments used by each teacher (implies the year or cycle definition of an instrument matrix).

- Completion rate for evaluation criteria (checklists).

- Common instruments used: different classes and the same year subject (checklist).

- Comparative analysis of student results from the same year and subject of schooling.

\section{Differentiation and Support:}

- Number of devices used per student with special educational needs.

- Number of additional articulations between group directors or classmates, parents and technical and special education staff. 
- Number of students with special educational needs enrolled.

- Number of educational activities, curriculum and enrichment in school time (number of students enrolled).

\subsection{Domain 3 - Organization and School Management}

\section{Design, Planning and Development of the Activity:}

- Number of educational projects articulated and annual plan for activities; educative project, curricular project, or school group curricular project.

- Periodicity of school newsletter publication.

- Subject identification in different groups (subject/level).

\section{Human Resource Management:}

- Grouping of teacher's academic degrees.

- Student rate by teachers.

- Number of teaching staff training credits and non-teaching staff training credits for the academic year.

- Grouping of training needs identified by knowledge field.

- Teachers that have the same classes year after year, and the number of academic years involved (pedagogical continuity).

\section{Financial and Material Resource Management:}

- Rate of classroom occupancy.

- Rate of computer utilization.

- Ratio of computers per student.

- Rate of gymnasium occupation.

- Rate of arts facilities occupation.

- Amount of funds raised by the school.

Participation of Parents and Other Elements of the School Community:

- Rate of activities with parent participation in the annual plan of activities.

- Rate of parent delegate presence in the assembly.

- Number of initiatives to support parents' involvement in student homework.

\subsection{Domain 4 - Leadership}

\section{Vision and Strategy:}

- Rate of objectives accomplished within the timing defined.

\section{Motivation and Commitment:}

- Assiduity rate of teachers and staff.

\subsection{Domain 5 - Extras}

- Series of results per academic year (a weighted average over the last 3 years).

- Level of parent education (resulting from questionnaires launched at the beginning of the academic year). 
- Grouping of parental professions.

- Average age by K-level of students.

- Number of students supported by the social program.

- Percentage of students with internet access.

- K-level with most students.

- Percentage of students who drop-out from the school.

- Rate of student transiting to higher education.

- Annual expenditure per student.

- Cumulative expenditure per student over the course of studies.

- Percentage of own school capital in the school budget.

- Student cost per class.

- Foreign students enrolled.

- Student grouping by educational area.

- Average class size by cycles of studies.

- Average class size per year of schooling.

- Ratio of students per teacher, by educational level.

\section{Conclusions}

In this work, a decentralized model is advocated; a model in which data collection becomes the school's responsibility. It is also advocated that creativity and competitiveness should be fostered, as tools for developing and innovating each school's management information system. By themselves, or together with technological partners, schools from this project must collect data as presented in the VSM-adapted model. VSM and its recursion contain the same guiding data warehousing principles to satisfy modern information needs [17]. From strategies to operation, the VSMadapted model covers all school areas with its constituent elements. Communication between its elements and its functions is another aspect foreseen in this VSM adaptation. To accommodate future trends, the adapted model brings a corresponding element. It is through this element that architecture will be able to propose information to prepare for change.

A process of autonomy growth affecting schools in Portugal is already in progress [9]. The focus of our study was strongly influenced by this process. The research line defined focuses on remodelling information system architecture in order to support school autonomy to develop information management while serving schools, communities and the Ministry. The proposed model reverses the logic of standards present in our educational system. The information standards are only used to satisfy the Ministry's information needs and that information must be provided. The architecture's remodelling respects and invests in school autonomy, understanding them as units of a complex educational system whose environmental relationship calls for a great variety in terms of action. It proposes an application of the viable systems model for the school, which respects its great variety and complexity, as well as the growing sense of autonomy of school systems.

This architectural model improves communication channels and control elements. By developing an element of intelligence, a school's capacity to adapt to contemporary needs is increased. This new element brings for a school a capacity to adapt to 
change, accompanying environmental trends and technological developments. The reshaping of architecture is flexible in allowing strategic alignments, and with the inclusion of KPIs in the intelligence element, creates a basis for a brand new global referential.

With cloud computing, we are witnessing one more leap in technological evolution. This new technological generation was found to be an opportunity to bring the same accountability cloud to different schools, serving leaderships, communities and the Ministry. Recursion is present at all levels of the educational system, from the Ministry to the classroom. On the other hand, just as autonomy should be encouraged, accountability should be a requirement as well, and all schools should answer to it in a similar way. Considering this, we apply a template that invests in the autonomy of all functional units, but still meets accountability standards. This architectural facility performs, with the intelligence element, by providing the heads of functional units of the education system with access to a global observation of reality, enabling them to understand what really is happening through defined parameters.

Simultaneously, the path followed applies to the various units of the educational system, granting them an ability to provide information, thus enabling them to contribute to the construction of global knowledge, to support global definitions, areas of research and accountability, turning it into an increasing phenomenon in our societies. This architectural adapted model has a clearly decentralizing effect and brings benefits to schools for obvious reasons. The information industry may also find in education a new cluster to develop, as the option for no standard solution to educational systems and the increase of schools' freedom to choose bring important stimuli to the competitiveness between players in this particular market.

\section{References}

1. Neumann, J.V.O.N., Godfrey, M.D.: First Draft of a Report on the EDVAC. IEEE Annals of the History of Computing 15(4), 27-75 (1993)

2. Nolan, R.L.: Managing the computer resource: a stage hypothesis. Communications of the ACM 16(7), 399-405 (1973)

3. Sowa, J.F., Zachman, J.A.: Extending and formalizing the framework for information systems architecture. IBM Systems Journal 31(3), 590-616 (1992)

4. Lange, A., Breiter, A.: Bringing order to chaos. In: Tatnall, C., Visscher, A., Finegan, A., O'Mahony, C. (eds.) Evolution of Information Technology in Educational Management, pp. 1-14. Springer (2009)

5. Henderson, J.C., Venkatraman, N.: Strategic alignment: Leveraging information technology for transforming organizations. IBM Systems Journal 32(1), 472-484 (1999)

6. Beer, S.: The Viable System Methodology and Pathology. Journal of the Operational Research Society 35, 7-25 (1984)

7. Beer, S.: The heart of enterprise, pp. 214-217. John Wiley \& Sons, Chichester (1994)

8. Beer, S.: Brain of the Firm, 2nd edn. John Wiley \& Sons, Chichester (1981)

9. Eurydice, a Rede de Informação sobre Educação na Europa: Autonomia das Escolas na Europa Políticas e Medidas. Lisboa, Portugal (Dezembro 2007)

10. Espejo, R., Reyes, A.: Managing Complexity with the Viable System Model, p. 264. Springer, Berlin (2011) 
11. Beer, S.: Diagnosing the system for organisations. John Wiley \& Sons, Chichester (1995)

12. Visscher, A.J.: A framework for studying school performance feedback systems. In: Visscher, A., Coe, R. (eds.) School Improvement Through Performance Feedback, pp. 41-72. Routledge (2002)

13. O’Mahony, C.D.: Two Approaches. In: Tatnall, A., Visscher, A., Finegan, A., O’Mahony, C. (eds.) Evolution of Information Technology in Educational Management, pp. 15-22. Springer, Heidelberg (2009)

14. Taylor, C., Fitz-Gibbon, C.: A Typology of Indicators. In: Visscher, A., Coe, R. (eds.) School Improvement Through Performance Feedback, pp. 27-39. Routledge (2002)

15. IGE: Avaliação Externa das Escolas - Referentes e instrumentos de trabalho, Lisboa, Portugal, pp. 19-39 (2009)

16. OECD: Education at a Glance. OECD Publishing (2011)

17. Inmon, W.H., Zachman, J.A., Geiger, J.G.: Data stores, data warehousing, and the Zachman Framework: managing enterprise knowledge, p. 128. McGraw-Hill (1997) 